\title{
Exercise electrocardiographic responses and serum cystatin $C$ levels among metabolic syndrome patients without overt diabetes mellitus
}

\author{
This article was published in the following Dove Press journal: \\ Vascular Health and Risk Management \\ 4 February 2011 \\ Number of times this article has been viewed
}

\author{
Asli Tanindi ${ }^{\prime}$ \\ Hilal Olgun' \\ Ayse Tuncel ${ }^{2}$ \\ Bulent Celik ${ }^{3}$ \\ Hatice Pasaoglu ${ }^{2}$ \\ Bulent Boyaci' \\ 'Department of Cardiology, \\ ${ }^{2}$ Department of Medical Biochemistry, \\ Faculty of Medicine, ${ }^{3}$ Department of \\ Statistics, Faculty of Health Sciences, \\ Gazi University, Ankara, Turkey
}

\begin{abstract}
Objectives: An impaired heart rate response during exercise (chronotropic incompetence) and an impaired heart rate recovery (HRR) after exercise are predictors of cardiovascular risk and mortality. Cystatin $\mathrm{C}$ is a novel marker for cardiovascular disease. We aimed to investigate exercise electrocardiographic responses in patients with metabolic syndrome who were without overt diabetes mellitus, in addition to the association of serum cystatin $\mathrm{C}$ levels with the exercise electrocardiographic test results.
\end{abstract}

Method: Forty-three consecutive patients admitted to a cardiology outpatient clinic without angina pectoris were recruited if they met criteria for metabolic syndrome but did not have overt diabetes mellitus. Serum cystatin $C$ levels were measured, and all participants underwent exercise electrocardiographic testing. Patients who were found to have ischemia had a coronary angiography procedure.

Results: The mean cystatin $\mathrm{C}$ level of patients was higher in metabolic syndrome group than healthy controls $(610.1 \pm 334.02$ vs $337.3 \pm 111.01 \mu \mathrm{g} / \mathrm{L} ; P<0.001)$. The percentage of patients with ischemia confirmed by coronary angiography was $13.9 \%$ in the metabolic syndrome group. Cystatin $\mathrm{C}$ levels in the ischemic patients of the metabolic syndrome group were higher than that in nonischemic patients $(957.00 \pm 375.6$ vs $553.8 \pm 295.3 \mu \mathrm{g} / \mathrm{L} ; P=0.005)$. Chronotropic incompetence was observed in $30.2 \%$ of the patients with metabolic syndrome compared with $16.7 \%$ in the control group $(P=0.186)$. Chronotropic response indices were $0.8 \pm 0.18$ versus $0.9 \pm 0.10$ for the two groups, respectively $(P=0.259)$. HRR was significantly lower in the metabolic syndrome patients compared with the controls $(20.1 \pm 8.01$ vs $25.2 \pm 4.5$ per min; $P<0.001)$, and the ST-segment adjustment relative to heart rate(ST/HR index ratio) was $1.4 \pm 1.34$ versus $0.4 \pm 0.31 \mu \mathrm{V} /$ beat $(P<0.001)$, respectively. Cystatin $\mathrm{C}$ was negatively correlated with the chronotropic response index (CRI) and HRR and was positively correlated with ST/HR index in the entire study population $(R=-0.658,-0.346,0.388$, respectively; $P<0.05)$.

Conclusions: A substantial proportion of metabolic syndrome patients without overt diabetes mellitus had silent coronary ischemia in addition to impairment of objective exercise electrocardiographic parameters. In the metabolic syndrome patients without overt diabetes mellitus, cystatin $\mathrm{C}$ levels were found to be elevated and the elevation was more pronounced in the subgroup with silent ischemia. Cystatin C was also correlated with HRR and CRI.

Keywords: exercise electrocardiography, metabolic syndrome, silent ischemia, cystatin C

\section{Introduction}

Metabolic syndrome, which consists of abdominal obesity, low levels of high-density lipoprotein, high blood pressure, high blood glucose, and high triglyceride levels, 
has become an increasingly important risk factor for cardiovascular morbidity and mortality. ${ }^{1}$ Recently, it was reported that exercise electrocardiographic responses are strong predictors of cardiovascular risk and mortality in the presence of metabolic syndrome components and this relationship increased with the number of present metabolic syndrome components. ${ }^{2}$

Chronotropic incompetence, (CI) defined as 'the inability to achieve $85 \%$ of the age-predicted maximum heart rate', has been shown to be associated with cardiovascular risk and cardiac mortality. ${ }^{3}$ It has also been reported that autonomic nervous system-related chronotropic incompetence during exercise is influenced by endothelial dysfunction as represented by flow-mediated dilation. ${ }^{4}$ Heart rate recovery (HRR), another parameter evaluated during exercise testing, is a marker of impaired parasympathetic reactivity and has been studied in patients with metabolic syndrome or metabolic risk factors. . $^{5,6}$

Cystatin C, which is a novel indicator of renal glomerular filtration rate, has recently been shown to be associated with metabolic syndrome, diabetes, and prediabetes. ${ }^{7-9}$ Cystatin $\mathrm{C}$ levels have been found to be superior to creatinine or creatinine-based formulas for the prediction of cardiovascular events and all-cause mortality. ${ }^{10}$ The association of cystatin $\mathrm{C}$ with insulin resistance, metabolic syndrome, and endothelial dysfunction, ${ }^{11}$ in addition to a number of inflammatory biomarkers, ${ }^{12,13}$ is the likely link between cardiovascular disease and cystatin $\mathrm{C}$.

We chose to study metabolic syndrome patients without known coronary artery disease or overt diabetes mellitus because diabetes is considered to be a coronary artery disease risk equivalent. We sought to investigate the impact of metabolic syndrome on exercise electrocardiographic stress test parameters, especially regarding chronotropic incompetence, chronotropic response index (CRI), and HRR. In addition, we examined the association of cystatin $\mathrm{C}$ in metabolic syndrome without overt diabetes and the prementioned exercise test parameters regarding the early detection of cardiovascular disease and risk prediction.

\section{Patients and methods}

Forty-three consecutive patients admitted to the outpatient clinic of the Cardiology Department of Gazi University Faculty of Medicine Hospital between September 2009 and February 2010 were recruited only if they did not have angina pectoris or any angina equivalent and if they met the criteria for metabolic syndrome but did not exhibit overt diabetes mellitus. Patients were enrolled if they had impaired glucose tolerance. Metabolic syndrome was defined according to the American Heart Association and the National Heart, Lung, and Blood Institute criteria. ${ }^{14}$ Patients with three or more of the following risk factors were considered to have metabolic syndrome: 1) abdominal obesity ( $>102 \mathrm{~cm}$ in men and $>88 \mathrm{~cm}$ in women), 2) low high-density lipoprotein levels ( $<40 \mathrm{mg} / \mathrm{dL}$ for men and $<50 \mathrm{mg} / \mathrm{dL}$ for women), 3) high triglyceride levels $(>150 \mathrm{mg} / \mathrm{dL}), 4)$ high fasting plasma glucose levels $(>100 \mathrm{mg} / \mathrm{dL})$, and 5) high blood pressure $(\geq 130 / 85 \mathrm{~mm} \mathrm{Hg}$ ). Baseline biochemical examinations were performed after $12 \mathrm{~h}$ of fasting. Blood pressures were recorded in the outpatient clinic after $10 \mathrm{~min}$ of rest. Waist circumference was measured at the level of the umbilicus using a standard anthropometric tape measure. Patients with known diabetes mellitus, previous coronary artery disease, cerebrovascular disease, moderate to severe valvular pathology, heart failure, hyperthyroidism, hypothyroidism, left bundle branch block, Wolff-Parkinson-White syndrome, any rhythm other than sinus rhythm on baseline electrocardiography (atrial fibrillation, atrial flutter, etc.), impaired renal function (serum creatinine $>1.4 \mathrm{mg} / \mathrm{dL}$ ), or impaired liver function (aspartate aminotransferase/alanine aminotransferase elevation $>3$ times the upper limit) were excluded.

The control group comprised healthy individuals admitted to the institutional blood transfusion center of the hospital as voluntary blood donors. The study was conducted according to the guidelines of the Declaration of Helsinki, and it was approved by the Institutional Ethics Committee. All of the participants provided written informed consent.

Blood samples for cystatin $\mathrm{C}$ measurements were centrifuged and kept at $-80^{\circ} \mathrm{C}$ until they were measured using the Human Cystatin C ELISA assay (BioVendor, Modrice, Czech Republic) according to the manufacturer's protocols. Both intra-assay and inter-assay coefficient of variations were $<5 \%$.

Exercise testing was performed according to the Bruce protocol with an AT-10 Exercise Testing System (Schiller, Baar, Switzerland). A 12-lead electrocardiography study was obtained throughout the procedure, and heart rate was monitored from the beginning of testing to the end of the recovery period. Blood pressure measurements were made at the beginning of testing, at every stage, and during the recovery period. The target heart rate for each participant was calculated before the procedure according to the following formula for age-predicted maximum heart rate: 220 - age. Exercise capacity was represented as the maximal metabolic equivalent (MET) achieved during exercise. The Duke score, which has been validated as an important 
predictor of mortality, ${ }^{15}$ was calculated for each participant according to the following formula: Duke treadmill score $(D T S)=$ the duration of exercise $($ in minutes $)-(5 \times$ maximal ST segment deviation $)-(4 \times$ angina score $)$. (Angina score: $0=$ no angina, $1=$ nontest-limiting angina, $2=$ exerciselimiting angina.) Chronotropic incompetence was defined as a 'failure to achieve $85 \%$ of age predicted maximum heart rate'. The CRI, which is a measure of maximal heart rate in relation to chronotropic reserve, was calculated using the formula: (peak heart rate - resting heart rate)/(age - age predicted maximum heart rate - resting heart rate). ${ }^{16}$ HRR was defined as a decrease in the heart rate from peak exercise rate to $1 \mathrm{~min}$ after cessation of exercise. ${ }^{17}$ Exercise test results regarding ischemia were interpreted as either ischemic, equivocally ischemic, or normal. The criteria for classifying an exercise stress test as 'ischemic' have been provided elsewhere. ${ }^{18} \mathrm{We}$ categorized an exercise stress test result as 'equivocal' if ST segment depressions of $0.5-1 \mathrm{~mm}$ were observed to persist for more than $0.08 \mathrm{sec}$. Participants with ischemic or equivocal test results underwent coronary angiography by Judkins technique, which was performed using a Toshiba Infinix CSI device (Toshiba, Tokyo, Japan) using $6 \mathrm{~F}$ catheters via femoral route. Coronary angiographic evaluation was performed by two blinded cardiologists offline; in the case of any disagreement, a third cardiologist was consulted. The presence of $>70 \%$ coronary stenosis was defined as definite ischemia.

\section{Statistical analysis}

SPSS for Windows (version 15; SPSS, Chicago, IL) was used for statistical analyses. Continuous variables, such as cystatin C levels, CRI, HRR, and the ST/HR index, were expressed as means \pm standard deviation, whereas percentages and frequencies were used to express categorical variables, such as the presence of ischemia or metabolic syndrome. A $\chi^{2}$ test and Fischer's exact test were used for the analysis of categorical variables. For continuous variables, parametric test conditions were first tested. The Shapiro-Wilk test was used to examine whether continuous variables were normally distributed. For the analysis of the difference between two groups, Student's $t$-test and Mann-Whitney $U$ test were employed according to the parametric test conditions. The degree of association between continuous variables was calculated by a Spearman's 'rho' correlation coefficient. The area under curve (AUC) and $95 \%$ confidence intervals for cystatin C were evaluated by receiver operating characteristic (ROC) analysis. The best cut-off point for cystatin $\mathrm{C}$ was also calculated. A $P$ value $<0.05$ was considered to be statistically significant.

\section{Results}

Baseline characteristics of the study population are provided in Table 1. The mean age of metabolic syndrome patients $(52.4 \pm 10.5)$ was higher than the control group ( $38.0 \pm 6.5)$, whereas the ratio of males to females were comparable ( $23.3 \%$ vs $36.7 \%, P=0.213)$. The mean cystatin C levels were higher in metabolic syndrome patients than in healthy controls $(610.1 \pm 334.02$ vs $337.3 \pm 111.01 \mu \mathrm{g} / \mathrm{L} ; P<0.001)$. When a ROC curve analysis was performed, the cut-off value for cystatin C was $374.5 \mu \mathrm{g} / \mathrm{L}$ (Figure 1). The AUC was 0.824 (95\% CI 0.728-0.921, $P<0.001$ ). According to this cut-off point, $81.4 \%$ of the patients with metabolic syndrome had 'high' cystatin C levels, whereas only $23.3 \%$ of the patients without metabolic syndrome had levels $>374.5 \mu \mathrm{g} / \mathrm{L}$. When cystatin $\mathrm{C}$ levels were grouped according to the number of metabolic syndrome components present, it was found that cystatin $\mathrm{C}$ levels increased with the number of components (Table 2). However, the difference in cystatin $\mathrm{C}$ levels of patients who met at least three criteria for metabolic syndrome was nonsignificant.

Of the patients with metabolic syndrome, $55.8 \%$ completed the exercise test at stage III, and $63.4 \%$ of healthy controls achieved the same level. In contrast, $14 \%$ of metabolic

Table I Baseline characteristics of the study population

\begin{tabular}{|c|c|c|c|}
\hline & MS $(+)(n=43)$ & MS $(-)(n=30)$ & $P$ \\
\hline Age & $52.4 \pm 10.58$ & $38.0 \pm 6.489$ & 0.000 \\
\hline Gender (M/F) (\%) & $10 / 33(23.3 / 76.7)$ & $11 / 19(36.7 / 63.3)$ & 0.213 \\
\hline Smoker (\%) & 34.9 & 40.0 & 0.656 \\
\hline Family history (\%) & 23.3 & 26.7 & 0.739 \\
\hline \multicolumn{4}{|l|}{ Drugs used } \\
\hline$\beta$-blocker (\%) & 10.6 & 6.7 & 0.114 \\
\hline ACE I (\%) & 58.1 & 16.7 & 0.000 \\
\hline ASA (\%) & 14.0 & 10.0 & 0.613 \\
\hline Statin (\%) & 9.3 & 13.3 & 0.588 \\
\hline ECG ischemia (\%) & 16.3 & - & - \\
\hline BMI & $32.6(5.17)$ & 25.7 (1.94) & 0.000 \\
\hline $\begin{array}{l}\text { Waist } \\
\text { circumference }\end{array}$ & $108.0(11.80)$ & $85.0(6.72)$ & 0.000 \\
\hline $\mathrm{Hb}$ & $13.6(1.59)$ & $13.2(1.14)$ & 0.300 \\
\hline WBC & 7308.1 (I737.20) & 7294.0 (I I 02.72) & 0.969 \\
\hline \multirow[t]{2}{*}{ Plt } & $273,069.8$ & $297,333.3$ & 0.112 \\
\hline & $(65,653.27)$ & $(60,149.43)$ & \\
\hline Fasting glucose & $102.9(9.12)$ & $88.5(10.45)$ & 0.000 \\
\hline BUN & $14.5(3.86)$ & $27.9(3.03)$ & 0.000 \\
\hline Creatinine & $0.8(0.16)$ & $0.8(0.15)$ & 0.207 \\
\hline Uric acid & $4.9(1.42)$ & $4.3(0.35)$ & 0.029 \\
\hline $\mathrm{HDL}$ & $4 I .5(7.74)$ & $50.2(7.88)$ & 0.000 \\
\hline LDL & $129.9(37.43)$ & I 30.4 (8.93) & 0.937 \\
\hline TG & $181.8(63.36)$ & I49.0 (13.83) & 0.007 \\
\hline
\end{tabular}

Abbreviations: MS, metabolic syndrome; ACE, angiotensin-converting enzyme; ASA, acetylsalicylic acid; ECG, electrocardiogram; BMI, body mass index; $\mathrm{Hb}$, hemoglobin; WBC, white blood cells; Plt, platelets; BUN, blood urea nitrogen; HDL, high-density lipoprotein; LDL, low-density lipoprotein; TG, triglycerides. 


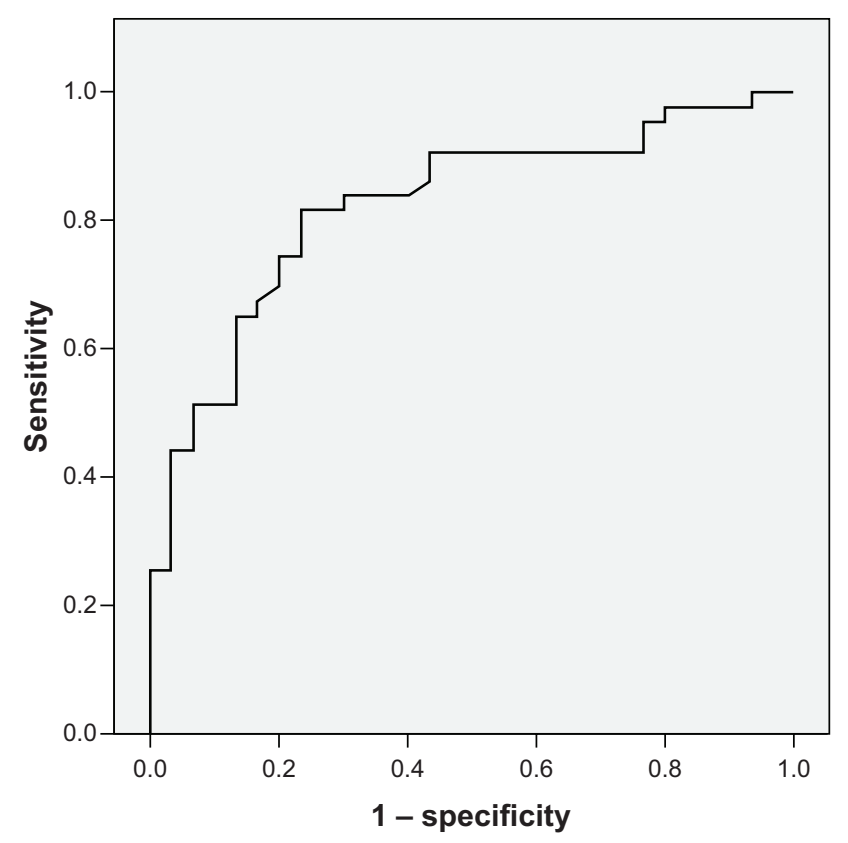

Figure I Receiver operating characteristic (ROC) curve analysis for cystatin C levels. The cut-off point for cystatin $\mathrm{C}$ was $374.5 \mu \mathrm{g} / \mathrm{L}$.

syndrome patients and $33 \%$ of healthy controls reached stage IV. Table 3 shows the exercise electrocardiographic results of the study and control groups. Chronotropic incompetence was observed in $30.2 \%$ of patients with metabolic syndrome compared with $16.7 \%$ in the control group $(P=0.186)$. Chronotropic response indices were $0.8 \pm 0.18$ versus $0.9 \pm 0.10$, respectively $(P=0.259)$. HRR was significantly lower in the metabolic syndrome patients compared with the controls ( $20.1 \pm 8.01$ vs $25.2 \pm 4.5$ per min, $P<0.001)$. The ST/HR index ratio was $1.4 \pm 1.34$ versus $0.4 \pm 0.31 \mu \mathrm{V} /$ beat, respectively $(P<0.001)$. Table 4 shows the results from the exercise test regarding ischemia (ischemic, normal, or equivocal). The percentage of patients with an equivocal or ischemic exercise test was $30.2 \%$ in the metabolic syndrome

Table 2 Mean cystatin $C$ levels with respect to the number of metabolic syndrome components present

\begin{tabular}{llllll}
\hline $\begin{array}{l}\text { No. of metabolic } \\
\text { syndrome } \\
\text { components }\end{array}$ & $\mathbf{N}$ & $\begin{array}{l}\text { Cystatin C } \\
\mu \mathrm{g} / \mathrm{L} \text { (mean) }\end{array}$ & SD & Min & Max \\
\hline None & 8 & 358.50 & 84.490 & 223 & 488 \\
$1 / 5$ & 16 & 305.44 & 83.034 & 126 & 456 \\
$2 / 5$ & 6 & 393.83 & 181.645 & 283 & 754 \\
$3 / 5$ & 16 & 613.63 & 379.026 & 261 & 1335 \\
$4 / 5$ & 19 & 627.16 & 318.695 & 224 & 1348 \\
$5 / 5$ & 8 & 562.50 & 311.446 & 274 & 1137 \\
Total & 73 & 497.97 & 297.178 & 126 & 1348 \\
\hline
\end{tabular}

Note: The difference between I criterion and 3 criteria and the difference between I criterion and 4 criteria are statistically significant $(P<0.05)$.

Abbreviation: SD, standard deviation.
Table 3 Exercise electrocardiographic test results of participants with and without metabolic syndrome

\begin{tabular}{lccl}
\hline & MS $(+)(\mathbf{n}=\mathbf{4 3})$ & MS $(-)(\mathbf{n}=\mathbf{3 0})$ & $\boldsymbol{P}$ \\
\hline Duke score & $2.3 \pm 4.27$ & $8.8 \pm 3.09$ & $\mathbf{0 . 0 0 0}$ \\
MET & $8.3 \pm 1.69$ & $9.6 \pm 1.59$ & $\mathbf{0 . 0 0 1}$ \\
Exercise duration (min) & $6.5 \pm 1.71$ & $10.5 \pm 1.50$ & $\mathbf{0 . 0 0 0}$ \\
Initial HR & $90.0 \pm 13.20$ & $78.0 \pm 7.34$ & $\mathbf{0 . 0 0 0}$ \\
Max HR & $154.4 \pm 20.99$ & $170.3 \pm 13.93$ & $\mathbf{0 . 0 0 1}$ \\
APMHR & $167.1 \pm 10.99$ & $181.9 \pm 6.50$ & $\mathbf{0 . 0 0 0}$ \\
CRI & $0.8 \pm 0.18$ & $0.9 \pm 0.10$ & 0.259 \\
HRR & $20.1 \pm 8.01$ & $25.2 \pm 4.50$ & $\mathbf{0 . 0 0 0}$ \\
ST/HR & $1.4 \pm 1.34$ & $0.4 \pm 0.31$ & $\mathbf{0 . 0 0 0}$ \\
\hline
\end{tabular}

Abbreviations: $M E T$, metabolic equivalent; $H R$, heart rate; APMHR, age-predicted maximum heart rate; CRI, chronotropic response index; ST/HR, ST-HR index; MS, metabolic syndrome.

population, but only $13.9 \%$ of metabolic syndrome patients had definite ischemia detected by coronary angiography. None of the participants in the control group had definite ischemia. Table 5 shows the exercise test parameters of metabolic syndrome patients and the entire population with or without ischemia. We were unable to show significant differences in the mean CRI and the HRR time between ischemic and nonischemic patients within the metabolic syndrome group; however, these parameters were significantly different in the entire study population.

Cystatin C levels in the ischemic patients of the metabolic syndrome group were higher than levels in the nonischemic patients $(957.00 \pm 375.6$ vs $553.8 \pm 295.3 \mu \mathrm{g} / \mathrm{L} ; P=0.005)$. Cystatin $C$ was negatively correlated with the CRI and HRR and was positively correlated with the ST/HR index in entire study population $(\mathrm{R}=-0.658, \mathrm{R}=-0.346$, and $\mathrm{R}=0.388$, respectively; $P<0.05)$. When patients with metabolic syndrome were separately evaluated, cystatin $\mathrm{C}$ levels were negatively correlated with the $\mathrm{CRI}(\mathrm{R}=-0.737, P<0.05)$ (Figure 2), but the correlation with HRR and the ST/HR index did not reach statistical significance.

\section{Discussion}

The major finding of this study was the presence of silent ischemia in $13.9 \%$ of patients with metabolic syndrome but without overt diabetes mellitus. The mean cystatin $\mathrm{C}$ level

Table 4 Exercise test results of the study population with and without metabolic syndrome

\begin{tabular}{lll}
\hline Exercise test results & \multicolumn{2}{l}{ Metabolic syndrome } \\
\cline { 2 - 3 } & Present $(\mathbf{n}=\mathbf{4 3})$ & Absent $(\mathbf{n}=\mathbf{3 0})$ \\
\hline Ischemia (N/\%) & $6(13.9)$ & - \\
Normal (N/\%) & $30(69.7)$ & $25(83.3)$ \\
Equivalent (N/\%) & $7(16.4)$ & $5(16.7)$ \\
\hline
\end{tabular}


Table 5 Exercise electrocardiographic test results according to the presence or absence of ischemia in metabolic syndrome patients and the entire study population

\begin{tabular}{lllllll}
\hline & Ischemia & N & Mean & SD & U & $P$ \\
\hline MET S(+) only & & & & & & \\
CRI & $(-)$ & 37 & 0.84 & 0.166 & 61.00 & 0.083 \\
& $(+)$ & 6 & 0.66 & 0.233 & & \\
HRR (beats/min) & $(-)$ & 37 & 20.70 & 8.299 & 75.00 & 0.220 \\
& $(+)$ & 6 & 16.33 & 4.885 & & \\
ST/HR ( $\mu$ V/beat) & $(-)$ & 37 & 1.14 & 1.127 & 32.00 & 0.004 \\
& $(+)$ & 6 & 2.95 & 1.612 & & \\
Entire population & & & & & & \\
CRI & $(-)$ & 67 & 0.86 & 0.140 & 103.00 & 0.046 \\
& $(+)$ & 6 & 0.66 & 0.242 & & \\
HRR (beats/min) & $(-)$ & 67 & 22.70 & 7.173 & 83.50 & 0.018 \\
& $(+)$ & 6 & 16.33 & 4.885 & & \\
ST/HR ( $\mu \mathrm{V} /$ beat) & $(-)$ & 67 & 0.79 & 0.940 & 38.00 & 0.001 \\
& $(+)$ & 6 & 2.95 & 1.612 & & \\
\hline
\end{tabular}

Abbreviations: MET, metabolic equivalent; CRI, chronotropic response index; HRR, heart rate recovery.

was higher in metabolic syndrome patients than in healthy controls. Moreover, cystatin $\mathrm{C}$ levels in ischemic patients within the metabolic syndrome group were higher than in nonischemic patients. The $13.9 \%$ prevalence of silent ischemia in our study is lower than percentages reported for diabetic patients. ${ }^{19,20}$ To our knowledge, this study is the first to report the frequency of silent ischemia in metabolic syndrome patients without overt diabetes mellitus. Although our report highlights the presence of coronary ischemia

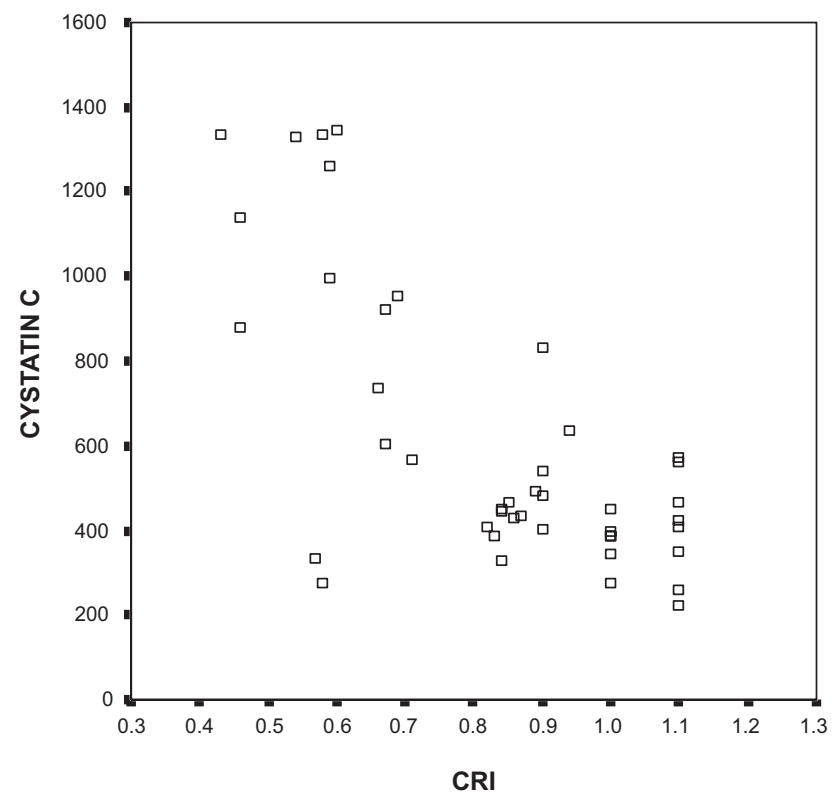

Figure 2 Scatter plot showing the correlation between cystatin $C$ and the chronotropic response index $(\mathrm{CRI})$. in a substantial proportion of the target population, this issue should be a topic for future research in larger study populations to confirm these results.

When objective parameters for the interpretation of exercise stress testing were analyzed, we observed that HRR was significantly impaired when compared with healthy controls. However, the difference between the percentage of participants with and without chronotropic incompetence and the chronotropic response indices of participants with or without metabolic syndrome did not reach statistical significance. Cystatin C was negatively correlated with the CRI and HRR and was positively correlated with ST/HR index.

Cystatin $\mathrm{C}$, a low molecular weight plasma protein that functions as an inhibitor of cysteine proteases, is produced by all nucleated cells, freely filtered by renal glomeruli and metabolized in the proximal tubules. ${ }^{21}$ Cystatin $\mathrm{C}$ has been shown to be a strong independent risk factor for cardiovascular mortality and a powerful prognostic factor among patients with known coronary artery disease. ${ }^{22,23}$ High cystatin $\mathrm{C}$ concentrations also predict cardiovascular risks in patients without microalbuminuria and with normal glomerular filtration rates, in addition to patients with renal damage. ${ }^{10}$ We have demonstrated an association between cystatin $\mathrm{C}$ and the presence of metabolic syndrome without overt diabetes mellitus. In addition, we report a positive correlation between this molecule and silent ischemia as well as some of the above-mentioned exercise electrocardiographic parameters. Recently cystatin $\mathrm{C}$ has been reported to be associated with endothelial dysfunction as represented by flow-mediated dilatation, ${ }^{24}$ in addition to its correlation with insulin resistance and inflammatory biomarkers. ${ }^{12,13,25}$ Although we cannot definitely suggest a causal relationship between cystatin $\mathrm{C}$ and silent ischemia or any of the exercise electrocardiographic findings due to the cross-sectional design of the study, endothelial dysfunction probably constitutes an important role in this process due to the fact that endothelium is the chief regulator of vascular homeostasis ${ }^{26}$ and plays a role in all stages of atherosclerosis. ${ }^{27} \mathrm{In}$ a recent study, 899 patients with known coronary artery disease and stable angina pectoris had underwent an exercise treadmill test with stress echocardiography, and elevated levels of cystatin $\mathrm{C}$ were associated with inducible ischemia. ${ }^{28}$

HRR after maximal exercise testing is a predictor of mortality and cardiovascular disease independent of the angiographic severity of coronary artery disease. ${ }^{29,30}$ Studies investigating HRR have expanded to include diabetic patients, patients with insulin resistance, and patients with metabolic risk factors. ${ }^{31-34}$ It has been suggested that short-term HRR 
(1-min HRR) reflects cardiac parasympathetic outflow, whereas a subsequent slow heart rate decay is associated with the withdrawal of sympathetic activity. ${ }^{35}$ There have been studies suggesting that autonomic dysfunction is associated with hyperinsulinemia, insulin resistance, and obesity ${ }^{36,37}$ and that the central nervous system contributes to the development of metabolic syndrome. However, the CARDIA study has revealed that a slower HRR does not precede the development of the metabolic syndrome, but, rather appears after components of the syndrome are present. ${ }^{5}$ In a recent study by Giallauria et al, in a population consisting of young women with polycystic ovary syndrome, abnormal HRR was associated with elevated white blood cell counts and C-reactive protein, a well-known inflammatory marker. ${ }^{38}$ Another report demonstrated that in patients with established coronary artery disease, Cystatin C concentrations were associated with decreased exercise capacity and lower HRR; 39 however, the participants in that study were largely elderly men. Our results support previous studies that suggest an impairment of HRR in the presence of metabolic disturbances or inflammation, but this relationship has now been demonstrated for the first time in an asymptomatic patient group with metabolic syndrome, without overt diabetes.

Chronotropic incompetence is defined by an attenuated heart rate response to exercise that has been shown to predict cardiovascular risk and mortality in healthy populations; even after adjusting for age, standard risk factors, and ST segment changes during exercise. ${ }^{40}$ Chronotropic incompetence has been believed to reflect a modulation of autonomic tone. It has been suggested that frequent activation of sympathetic nerves alters $\beta$-adrenergic sensitivity and causes postsynaptic $\beta$ desensitization, which subsequently leads to chronotropic incompetence during exercise. ${ }^{41,42}$ Another proposed mechanism is compensatory vagal hyperactivity during exercise. ${ }^{43}$ Huang et al reported that among patients who had undergone a treadmill exercise test for typical and atypical angina pectoris, the subgroup with chronotropic incompetence had endothelial dysfunction and enhanced systemic inflammation. ${ }^{4}$ We observed that cystatin $\mathrm{C}$ was correlated with chronotropic incompetence and the CRI, although the cross-sectional design of this study prevents a causal interpretation of this relationship.

In conclusion, in metabolic syndrome patients without overt diabetes mellitus, we have demonstrated the presence of silent ischemia in a substantial percentage of the study population as well as impairment in most of the exercise electrocardiographic parameters and an association between them and elevated serum cystatin $C$ levels. Cystatin C, an emerging biomarker for cardiovascular morbidity and mortality, may be used to identify higher risk subgroups within asymptomatic metabolic syndrome patients. These patients require aggressive risk factor modification and antiatherosclerotic treatment. Our findings are, therefore, significant, especially for clinicians and practitioners who often treat these patients in their clinical practice.

\section{Acknowledgment}

The ELISA assay used for the detection of serum Cystatin C levels was supplied by the IMSED (Internal Medicine Post Graduation Education Society)/Ankara/TURKEY.

\section{Disclosure}

The authors report no conflicts of interest in this work.

\section{References}

1. Servais A, Giral P, Bernard M, Bruckert E, Deray G, Isnard Bagnis C. Is serum cystatin-C a reliable marker for metabolic syndrome? Am JMed. 2008;121(5):426-432.

2. Lyerly GW, Sui X, Church TS, Lavie CJ, Hand GA, Blair SN. Maximal exercise electrocardiographic responses and coronary heart disease mortality among men with metabolic syndrome. Mayo Clin Proc. 2010; 85(3):239-246.

3. Fukuma N, Oikawa K, Aisu N, et al. Impaired baroreflex as a cause of chronotropic incompetence during exercise via autonomic mechanism in patients with heart disease. Int J Cardiol. 2004;97(3):503-508.

4. Huang PH, Leu HB, Chen JW, et al. Comparison of endothelial vasodilator function, inflammatory markers, and $\mathrm{N}$-terminal pro-brain natriuretic peptide in patients with or without chronotropic incompetence to exercise test. Heart. 2006;92(5):609-614.

5. Kizilbash MA, Carnethon MR, Chan C, Jacobs DR, Sidney S, Liu K. The temporal relationship between heart rate recovery immediately after exercise and the metabolic syndrome: the CARDIA study. Eur Heart $J$. 2006;27(13):1592-1596.

6. Lin LY, Kuo HK, Lai LP, Lin JL, Tseng CD, Hwang JJ. Inverse correlation between heart rate recovery and metabolic risks in healthy children and adolescents: insight from the National Health and Nutrition Examination Survey 1999-2002. Diabetes Care. 2008;31(5): 1015-1020.

7. Retnakaran R, Connelly PW, Harris SB, Zinman B, Hanley AJ. Cystatin C is associated with cardiovascular risk factors and metabolic syndrome in Aboriginal youth. Pediatr Nephrol. 2007;22(7):1007-1013.

8. Donahue RP, Stranges S, Rejman K, Rafalson LB, Dmochowski J, Trevisan M. Elevated cystatin C concentration and progression to pre-diabetes: the Western New York Study. Diabetes Care. 2007;30(7): 1724-1729.

9. Lee SH, Park SA, Ko SH, et al. Insulin resistance and inflammation may have an additional role in the link between cystatin $\mathrm{C}$ and cardiovascular disease in type 2 diabetes mellitus patients. Metabolism. 2010;59(2): 241-246.

10. Ix JH, Shlipak MG, Chertow GM, Whooley MA. Association of cystatin $\mathrm{C}$ with mortality, cardiovascular events, and incident heart failure among persons with coronary heart disease: data from the Heart and Soul study. Circulation. 2007;115(2):173-179.

11. Surendar J, Indulekha K, Aravindhan V, Ganesan A, Mohan V. Association of cystatin-C with metabolic syndrome in normal glucose-tolerant subjects (CURES-97). Diabetes Technol Ther. 2010;12(11):907-912.

12. Shlipak MG, Katz R, Cushman M, et al. Cystatin-C and inflammatory markers in the ambulatory elderly. Am J Med. 2005;118(12):1416. 
13. Keller C, Katz R, Cushman M, Fried LF, Shlipak M. Association of kidney function with inflammatory and procoagulant markers in a diverse cohort: a cross-sectional analysis from the Multi-Ethnic Study of Atherosclerosis (MESA). BMC Nephrol. 2008;9:9.

14. Grundy SM, Cleeman JI, Daniels SR, et al. American Heart Association; National Heart, Lung and Blood Institute. Diagnosis and management of the metabolic syndrome. An American Heart Association/National Heart, Lung, and Blood Institute Scientific Statement. Executive summary. Cardiol Rev. 2005;13(6):322-327.

15. Mark DB, Shaw L, Harrell FE Jr, et al. Prognostic value of a treadmill exercise score in outpatients with suspected coronary artery disease. N Engl J Med. 1991;325(12):849-853.

16. Okin PM, Lauer MS, Kligfield P. Chronotropic response to exercise. Improved performance of ST-segment depression criteria after adjustment for heart rate reserve. Circulation. 1996;94(12):3226-3231.

17. Cole CR, Blackstone EH, Pashkow FJ, Snader CE, Lauer MS. Heart-rate recovery immediately after exercise as a predictor of mortality. $N$ Engl J Med. 1999;341(18):1351-1357.

18. Gibbons RJ, Balady GJ, Beasley JW, et al. ACC/AHA guidelines for exercise testing: executive summary. A report of the American College of Cardiology/American Heart Association Task Force on Practice Guidelines (Committee on Exercise Testing). Circulation. 1997;96(1): 345-354.

19. Puel J, Valensi P, Vanzetto G, et al. ALFEDIAM; SFC. Identification of myocardial ischemia in the diabetic patient. Joint ALFEDIAM and SFC recommendations. Diabetes Metab. 2004;30(3 Pt 3): 3S3-3S18.

20. Wackers FJ, Young LH, Inzucchi SE, et al. Detection of Ischemia in Asymptomatic Diabetics Investigators. Detection of silent myocardial ischemia in asymptomatic diabetic subjects: the DIAD study. Diabetes Care. 2004;27(8):1954-1961.

21. Borges RL, Hirota AH, Quinto BMR, Ribeiro AB, Zanella MT, Batista MC. Is cystatin $\mathrm{C}$ a useful marker in the detection of diabetic kidney disease? Nephron Clin Pract. 2010;114(2):c127-c134.

22. Shlipak MG, Sarnak MJ, Katz R, et al. Cystatin C and the risk of death and cardiovascular events among elderly persons. $N$ Engl J Med. 2005;352(20):2049-2060.

23. Koenig W, Twardella D, Brenner H, Rothenbacher D. Plasma concentrations of cystatin $\mathrm{C}$ in patients with coronary heart disease and risk for secondary cardiovascular events: more than simply a marker of glomerular filtration rate. Clin Chem. 2005;51(2):321-327.

24. Reffelmann T, Krebs A, Ittermann T, et al. Mild renal dysfunction as a non-traditional cardiovascular risk factor?-Association of cystatin C-based glomerular filtration rate with flow-mediated vasodilation. Atherosclerosis. 2010;211(2):660-666.

25. Curhan G. Cystatin C: a marker for renal function or something more? Clin Chem. 2005;51(2):293-294.

26. Vita JA, Keaney JF Jr. Endothelial function: a barometer for cardiovascular risk? Circulation. 2002;106(6):640-642.

27. Alsheikh-Ali AA, Kitsios GD, Balk EM, Lau J, Ip S. The vulnerable atherosclerotic plaque: scope of the literature. Ann Intern Med. 2010; 153(6):387-395.

28. Deo D, Shlipak MG, Ix JH, Ali S, Schiller NB, Whooley MA. Association of cystatin $\mathrm{C}$ with ischemia in patients with coronary heart disease. Clin Cardiol. 2009;32(11):E18-E22.
29. Vivekananthan DP, Blackstone EH, Pothier CE, Lauer MS. Heart rate recovery after exercise is a predictor of mortality, independent of the angiographic severity of coronary disease. J Am Coll Cardiol. 2003; 42(5):831-838.

30. Morshedi-Meibodi A, Larson MG, Levy D, O’Donnell CJ, Vasan RS. Heart rate recovery after treadmill exercise testing and risk of cardiovascular disease events (The Framingham Heart Study). Am J Cardiol. 2002;90(8):848-852.

31. Cheng YJ, Lauer MS, Earnest CP, et al. Heart rate recovery following maximal exercise testing as a predictor of cardiovascular disease and all-cause mortality in men with diabetes. Diabetes Care. 2003;26(7): 2052-2057.

32. Nilsson G, Hedberg P, Jonason T, Lönnberg I, Ohrvik J. Heart rate recovery is more strongly associated with the metabolic syndrome, waist circumference, and insulin sensitivity in women than in men among the elderly in the general population. Am Heart J. 2007;154(3):460. e1-460.e7.

33. Lauer MS. Exercise testing for assessment of autonomic function Am Heart J. 2002;144(4):580-582.

34. Panzer C, Lauer MS, Brieke A, Blackstone E, Hoogwerf B. Association of fasting plasma glucose with heart rate recovery in healthy adults: a population-based study. Diabetes. 2002;51(3):803-807.

35. Buchheit M, Papelier Y, Laursen PB, Ahmaidi S. Noninvasive assessment of cardiac parasympathetic function: postexercise heart rate recovery or heart rate variability? Am J Physiol Heart Circ Physiol. 2007;293(1):H8-H10.

36. Peterson HR, Rothschild M, Weinberg CR, Fell RD, McLeish KR, Pfeifer MA. Body fat and the activity of the autonomic nervous system. N Engl J Med. 1988;318(17):1077-1083.

37. Gottsäter A, Ahmed M, Fernlund P, Sundkvist G. Autonomic neuropathy in Type 2 diabetic patients is associated with hyperinsulinaemia and hypertriglyceridaemia. Diabet Med. 1999;16(1):49-54.

38. Giallauria F, Orio F, Lombardi G, et al. Relationship between heart rate recovery and inflammatory markers in patients with polycystic ovary syndrome: a cross-sectional study. J Ovarian Res. 2009;2:3.

39. McManus D, Shlipak M, Ix JH, Ali S, Whooley MA. Association of cystatin $\mathrm{C}$ with poor exercise study and heart rate recovery: data from the Heart and Soul study. Am J Kidney Dis. 2007;49(3):365-372.

40. Lauer MS, Okin PM, Larson MG, Evans JC, Levy D. Impaired heart rate response to graded exercise. Prognostic implications of chronotropic incompetence in the Framingham Heart Study. Circulation. 1996; 93(8):1520-1526.

41. Lauer MS, Pashkow FJ, Larson MG, Levy D. Association of cigarette smoking with chronotropic incompetence and prognosis in the Framingham Heart Study. Circulation. 1997;96(3):897-903.

42. Srivastava R, Blackstone EH, Lauer MS. Association of smoking with abnormal exercise heart rate responses and long-term prognosis in a healthy, population-based cohort. Am J Med. 2000;109(1):20-26.

43. Ellestad MH. Chronotropic incompetence. The implications of heart rate response to exercise (compensatory parasympathetic hyperactivity?). Circulation. 1996;93(8):1485-1487.
Vascular Health and Risk Management

\section{Publish your work in this journal}

Vascular Health and Risk Management is an international, peerreviewed journal of therapeutics and risk management, focusing on concise rapid reporting of clinical studies on the processes involved in the maintenance of vascular health; the monitoring, prevention and treatment of vascular disease and its sequelae; and the involvement of

\section{Dovepress}

metabolic disorders, particularly diabetes. This journal is indexed on PubMed Central and MedLine. The manuscript management system is completely online and includes a very quick and fair peer-review system, which is all easy to use. Visit http://www.dovepress.com/ testimonials.php to read real quotes from published authors. 